\title{
Sleep and Delirium in Older Adults
}

\section{Sadaf Farasat ${ }^{1}$ • Jennifer J. Dorsch ${ }^{2,3} \cdot$ Alex K. Pearce $^{4}$ - Alison A. Moore ${ }^{5} \cdot$ Jennifer L. Martin ${ }^{6,7} \cdot$ Atul Malhotra $^{4}$. Biren B. Kamdar ${ }^{4}$}

Published online: 27 July 2020

(C) Springer Nature Switzerland AG 2020

\begin{abstract}
Purpose of Review Poor sleep and delirium are common in older patients but recognition and management are challenging, particularly in the intensive care unit (ICU) setting. The purpose of this review is to highlight current research on these conditions, their inter-relationship, modes of measurement, and current approaches to management.

Recent Findings Sleep deprivation and delirium are closely linked, with shared clinical characteristics, risk factors, and neurochemical abnormalities. Acetylcholine and dopamine are important neurochemicals in the regulation of sleep and wakefulness and their dysregulation has been implicated in development of delirium. In the hospital setting, poor sleep and delirium are associated with adverse outcomes; non-pharmacological interventions are recommended, but tend to be resource intensive and hindered by a lack of reliable sleep measurement tools. Delirium is easier to identify, with validated tools available in both ICU and non-ICU settings; however, an optimal treatment approach remains unclear. Antipsychotics are used widely to prevent and treat delirium, although the efficacy data are equivocal. Bundled non-pharmacologic approaches represent a promising framework for prevention and management.

Summary Poor sleep and delirium are common problems in older patients. While these phenomena appear linked, a causal relationship is not clearly established. At present, there are no established sleep-focused guidelines for preventing or treating delirium. Novel interventions are needed that address poor sleep and delirium, particularly in older adults.
\end{abstract}

Keywords Sleep $\cdot$ Delirium $\cdot$ Intensive care $\cdot$ Acetylcholine $\cdot$ Dopamine $\cdot$ Aging

This article is part of the Topical Collection on Sleep and Aging

Biren B. Kamdar

bkamdar@health.ucsd.edu

Sadaf Farasat

sfarasat@ health.ucsd.edu

Jennifer J. Dorsch

Jennifer.J.Dorsch@gmail.com

Alex K. Pearce

apearce@health.ucsd.edu

Alison A. Moore

alm123@health.ucsd.edu

Jennifer L. Martin

jennifer.martin@va.gov

Atul Malhotra

amalhotra@health.ucsd.edu
1 Division of Geriatrics and Gerontology, University of California San Diego, 9350 Campus Point Drive, La Jolla, CA 92037, USA

2 Johns Hopkins Medicine, Baltimore, MD, USA

3 Johns Hopkins Medicine, Howard County General Hospital, 5755 Cedar Ln, Columbia, MD 21044, USA

4 Division of Pulmonary, Critical Care and Sleep Medicine, University of California San Diego School of Medicine, 9300 Campus Point Drive \#7381, La Jolla, CA 92037-7381, USA

5 Division of Geriatrics and Gerontology, University of California San Diego, 9500 Gilman Drive, MC 0665, La Jolla, CA 92093-0665, USA

6 VA Greater Los Angeles Healthcare System, 16111 Plummer St. (11E), North Hills, CA 91343, USA

7 David Geffen School of Medicine at the University of California, Los Angeles, CA, USA 


\section{Introduction}

Over the past two decades, delirium, in particular in older adults ( $\geq 65$ years old) hospitalized in intensive care units (ICUs), has gained substantial attention as a common and major health problem. This attention has been driven, in part, by the rise in the older adult population, combined with an explosion in research highlighting numerous adverse consequences of delirium, including long-term cognitive, physical and mental health impairments, and early death. This knowledge has motivated efforts to better understand and to prevent delirium, highlighting poor sleep, and more specifically sleep/ wake disruption, as a common and potentially modifiable risk factor for delirium. Interest is growing in the delirium-sleep/ wake relationship, in particular their shared characteristics and mechanisms, bidirectional effects, and impact on outcomes in older adults. This review aims to provide an in-depth overview on this topic, focusing specifically on (1) delirium and (2) poor sleep in older adults; (3) the sleep-delirium connection; (4) tools to evaluate delirium and sleep; and (5) prevention and management of poor sleep and delirium. We conclude by highlighting areas for future research.

\section{Delirium}

\section{Epidemiology and Consequences}

Delirium, an acute, severe neuropsychiatric syndrome characterized by waxing and waning levels of consciousness and periods of inattention and confusion, has gained attention over the past 20 years as a major health problem. A sequela of illness, hospitalization, or post-surgical states, delirium complicates up to $11 \%$ of emergency department visits [1], 33\% of hospitalizations [2], and 70\% of intensive care unit stays among older adults [3]. While predisposing factors such as advanced age, medical comorbidities, and baseline cognitive impairment can predispose patients to delirium, many modifiable precipitating factors also contribute to delirium, including uncontrolled pain, dehydration, and polypharmacy $[4,5]$. In hospitalized patients, delirium leads to prolonged length of stay, increased hospital costs [6], long-term cognitive impairments, prolonged institutionalization $[7,8]$, and early death $[9$, 10]. Delirium is also costly, accounting for up to $\$ 152$ billion in annual US health care expenditures [11]. Due to its short- and long-term consequences and costs, delirium has been identified as a research priority by the American Geriatrics Society (AGS) and National Institute on Aging [12], and a quality-of-care predictor of survival in the Assessing Care of Vulnerable Elders Study (ACOVE) [13].

\section{Mechanism and Presentation}

While delirium is a multifactorial phenomenon, with several proposed pathophysiological mechanisms, mechanistic research has been slow in part due a lack of wellestablished animal models and an absence of easily obtainable biomarkers [14]. Among the neurological pathways hypothesized to precipitate delirium, one involves the prefrontal cortex, anterior cingulate, and basal ganglia, and another involves the parietal lobes, superior colliculus, and thalamic pulvinar nucleus [15]. More recently, a functional network comprised of several interconnected brain structures has been implicated in delirium [16]. Disturbances in these pathways lead to decreased cholinergic activity and dopaminergic excess, contributing to delirium [17]. The depressed cholinergic activity pathway is supported by the observation that anticholinergic medications precipitate delirium $[18,19]$, and dopaminergic excess based on the possible therapeutic effect on delirium of haloperidol, a potent dopamine antagonist [20]. Recently, the dopaminergic pathway has been a common target for pharmaceutical trials for delirium treatment and prevention [21]. Besides acetylcholine and dopamine, neurotransmitters serotonin, gamma-aminobutyric-acid (GABA), glutamate, histamine, and norepinephrine are also implicated in delirium, but their mechanisms are not well established $[20,22]$.

A pro-inflammatory pathway may also contribute to delirium [14], particularly in acutely ill patients with higher levels of inflammatory biomarkers (e.g., cytokines) [23]. Theoretically, this pro-inflammatory state disrupts the bloodbrain barrier, leading to tissue edema, neurotransmitter imbalance, and apoptosis leading to cognitive dysfunction [24].

Oxidative stress, another potential mechanism behind delirium, occurs when chronic hypoperfusion leads to a mismatch between oxygen delivery and consumption, leading to a rise in non-oxidative metabolism and accumulation of reactive and potentially toxic oxygen and nitrogen species [14]. Accumulation of these products can damage cerebral tissue, contributing to cerebral dysfunction and manifesting as delirium [25].

Once delirious, patients can exhibit either hyperactive, hypoactive, or mixed motoric subtypes [26]. In the ICU, hypoactive delirium predominates, characterized by reduced psychomotor activity, lethargy, and augmented GABA and melatonin activity [27]. In contrast, depressed GABA and melatonin often occur with hyperactive delirium, characterized by increased psychomotor activity, agitation, disruptive behavior, sleep-wake disruption, and hallucinations [28]. Patients with mixed delirium fluctuate between the hypoand hyperactive states. Recent research suggests that the hypoactive subtype portends a poor prognosis compared to the hyperactive form [29]. 


\section{Delirium in Older Adults}

The majority of delirium occurs in older ( $\geq 65$ years old) hospitalized adults, affecting up to 50\% [30] and 70\% [3] of older non-ICU and ICU patients, respectively. Delirium also commonly affects older patients in non-hospital nursing units and post-acute care facilities [31]. Advanced age is independently associated with delirium in the acute care setting [32], as dementia and mild cognitive impairment are often clinically unrecognized [33]. While the mechanism for increased risk of delirium in older adults is unclear, age-related neurodegeneration and associated alterations in acetylcholine, catecholamine, and serotonin may play a role.

As compared to their younger counterparts, older patients are at risk for worse delirium-associated outcomes [34]. Incident delirium predisposes patients to new and persistent cognitive deficits and can accelerate the development of dementia for those with pre-existing cognitive impairment [35]. In older adults, hospital-associated delirium increases the risk of accidental disruption of life-sustaining therapy (e.g., selfextubation) and longer duration of mechanical ventilation and ICU and hospital length of stay $[9,36,37]$. Decreased ability to perform activities of daily living and loss of functional independence is a common outcome of delirium lasting 5 or more days [8]. Incident delirium also increases the risk of mental health impairments including posttraumatic stress and depression [38]. As a consequence, delirium in older adults, and its associated cognitive, physical, mental health, and quality of life impairments, increases the risk of rehospitalization and early death $[39,40]$.

\section{Poor Sleep in Older Adults}

The remainder of this review will focus on the relationship of poor sleep, sleep/wake disruption, and delirium in older adults. Under normal circumstances, total sleep time declines until age 60 years, plateauing at 6 to $7 \mathrm{~h}$ a night [41]. However, with age, sleep becomes more fragmented, with a rise in N1 and N2 ("light") sleep and a corresponding decline in slow wave sleep (SWS) and rapid eye movement (REM), stages considered vital for rest and repair [42]. More N1/N2 and less SWS render older adults more susceptible to arousals and awakenings from noxious stimuli such as light, sound, and physical discomforts such as pain or urge to micturate. Hence, up to $50 \%$ of older adults experience poor sleep quality [43]. Moreover, approximately $5 \%$ of older adults have clinically significant insomnia and $20 \%$ have sleep apnea syndromes [44], further contributing to sleep disruption [45]. Finally, older patients with dementia exhibit greater N1 sleep, altered N2 architecture, and decreased SWS and REM compared to non-demented counterparts [44].

\section{Sleep in Hospitalized Older Adults}

For all hospitalized patients, sleep is generally poor quality, with sleep disorders, pain, anxiety, and acute illness representing predisposing factors, and hospital- and carerelated disruptions representing precipitating factors [46, 47]. Among modifiable disruptions, hospitalized patients have identified noise (59\%), nursing interruptions (30\%), uncomfortable beds (18\%), bright lights (16\%), and unfamiliar surroundings $(14 \%)$ as common reasons for poor sleep in the hospital $[48,49]$.

In older hospitalized adults, sleep quality is particularly poor, averaging 2.5 fewer hours than home [50]. Sleep quality is even worse in older patients hospitalized in ICUs, characterized by fragmentation, decreased or absent REM and SWS, preponderance of $\mathrm{N} 1$, and predominance during daytime hours $[44,51,52]$. In the ICU environment, frequent loud sounds, patient-care interactions, sleep-altering medications (i.e., sedative infusions), and mechanical ventilation contribute to disrupted sleep [53-56].

While the mechanism is not understood, poor sleep quality during hospitalization has been associated with adverse outcomes in older adults [57]. For example, poor hospital sleep quality is believed to hinder participation in self-care and rehabilitation activities during post-illness recovery [58], increasing older adults' risk of falls, functional impairment, institutionalization, and early death.

\section{The Sleep-Delirium Connection}

Though causal pathways remain elusive, sleep/wake disruption and delirium are believed to be tightly associated, with a bidirectional relationship that is accentuated with aging. Parallel symptoms have been noted in both sleep-deprived and delirious states, including fluctuating periods of inattention, mental status, and cognitive dysfunction [59, 60]. Attention and memory impairment, two key features of delirium, are also common after partial and total sleep deprivation [61, 62]. Additionally, poor sleep and delirium share many common risk factors, such as uncontrolled pain, stress, prolonged immobility, and acute illness [63]. Among medications, benzodiazepines are independently associated with delirium and disrupt sleep architecture by suppressing SWS and REM [64], with a dose-dependent effect [65]. Anticholinergic medications are also associated with delirium and REM suppression [66].

Despite overlapping factors, strong evidence regarding the association between poor sleep and delirium is lacking, particularly in hospitalized patients. Conflicting findings have been found in critically ill patients; however, studies have been limited substantially by unmeasured confounders and challenges in accurate, large-scale measurement (see Sleep 
and Delirium Measurement below) [67]. Perhaps the most compelling ICU study in 27 mechanically ventilated patients demonstrated a significant adjusted association between shorter versus longer REM duration, as measured using polysomnography, and incident delirium [55].

Several studies have evaluated the relationship between the pre-existing sleep disorders syndromes and postoperative delirium (POD). For example, two studies evaluating patients undergoing elective knee [68] and/or hip replacement surgery [69] showed that those with obstructive sleep apnea (OSA), versus those without, were more likely to develop delirium. Similarly, following cardiac surgery, sleep-disordered breathing has been associated with a 6-fold increase in delirium risk [70]. These data were synthesized in a recent systematic review and meta-analysis involving 12 studies, which suggested a pooled odds ratio of POD of 4.75 for patients with OSA, and 5.60 for unspecified sleep disorders [71]. While prior studies on POD were limited by lack of sleep measurement, a recent pilot study involving EEG recordings suggested an association of lower sleep time and higher sleep latency on postoperative day 1 and higher prevalence and severity of POD [72]. The underlying POD-sleep mechanism remains unclear and may involve factors such as hypoxia and stress. Some have speculated that that severe OSA may be associated with reduced cholinergic activity, a known delirium risk factor [19].

Although little mechanistic data exist on poor sleep precipitating delirium, several plausible pathways have been proposed. Sleep deprivation involves various specific areas of the brain, many of which are involved in the pathogenesis of delirium. In healthy volunteers undergoing 24-h sleep deprivation and PET imaging, decreased cerebral metabolism was noted in the prefrontal cortex, thalamus, and posterior parietal cortex, key brain areas involved in delirium [73]. Another study involving EEG demonstrated involvement of the frontal and parietal cortical areas in sleep-deprived subjects [74]. Similarly, from a neurohormonal standpoint, imbalances seen in delirium have been observed during sleep deprivation, including those involving acetylcholine and dopamine [75]. Dopaminergic activity rises after periods of sleep deprivation and is similarly upregulated in delirium [17].

Aside from acetylcholine and dopamine, melatonin and its precursors and breakdown products have received considerable attention in the context of the sleep-delirium relationship. Under normal circumstances, the amino acid tryptophan undergoes conversion to melatonin, and melatonin is subsequently released by the pineal gland in a circadian pattern. Melatonin release is strongly influenced by sleep-wake rhythms and zeitgebers such as ambient light, feeding schedules and social interactions, and tightly intertwines with other vital circadian processes, including rest-activity rhythms and transcription of genes necessary for cell repair, regeneration, and death. In the hospital setting, circadian misalignment is common and is considered a predisposing factor for delirium.
This theory is supported by several studies, including those linking lower tryptophan levels with incident delirium following cardiac surgery [76], and others demonstrating higher delirium incidence in patients with abolished circadian melatonin secretion $[77,78]$. Studies evaluating urinary 6sulphatoxymelatonin (6-SMT), a melatonin breakdown product, demonstrated lower 6-SMT levels in patients with hyperactive delirium and higher levels in hypoactive delirium, suggesting a relationship of melatonin and circadian misalignment with motoric subtypes of delirium [28].

\section{Tools to Evaluate Sleep and Delirium}

Feasible, large-scale modes of evaluation are vital for efforts aimed at better detecting, preventing, and treating poor sleep and delirium, and for future research focusing on the sleepdelirium relationship and associated outcomes. However, as delirium predominantly occurs in the inpatient setting, in particular the ICU, measurement of both delirium and sleep is extremely complicated, hindered by logistical and confounding factors inherent to the busy hospital environment. The primary modes of measurement are summarized below and in Tables 1 and 2.

\section{Polysomnography}

The gold standard for measuring sleep in non-critically ill populations is polysomnography (PSG), which involves electroencephalography, electrooculography, electromyography, respiratory, oxygen saturation, and electrocardiography. Despite its utility, PSG is costly, cumbersome, resource intensive, and prone to electrode dislodgement, particularly in hospitalized or critically ill patients [79]. Additionally, in critically ill patients, the presence of severe sleep fragmentation [80], daytime sleep [53, 81], and atypical EEG patterns [82] makes PSG vulnerable to misinterpretation using traditional scoring criteria. For example, sleep spindles, which characterize N2 sleep, commonly occur with administration of benzodiazepines, while delta wave activity (as seen in SWS (N3)) can be seen in the setting of encephalopathy (i.e., secondary to toxic-metabolic disturbances or hepatic dysfunction). Hence, traditional sleep staging should be applied cautiously in ICU patients. An ICU-specific PSG scoring algorithm has been proposed but has yet to gain widespread use [82, 83].

\section{Electroencephalography and Odds Ratio Product}

Electroencephalography (EEG) utilizes scalp electrodes to measure brain activity, without EMG, EOG, and other monitors, and is therefore less cumbersome than PSG [84]. In noncritically ill patients, EEG and PSG are highly sensitive and specific for delineating wake versus sleep, with EEG lacking 


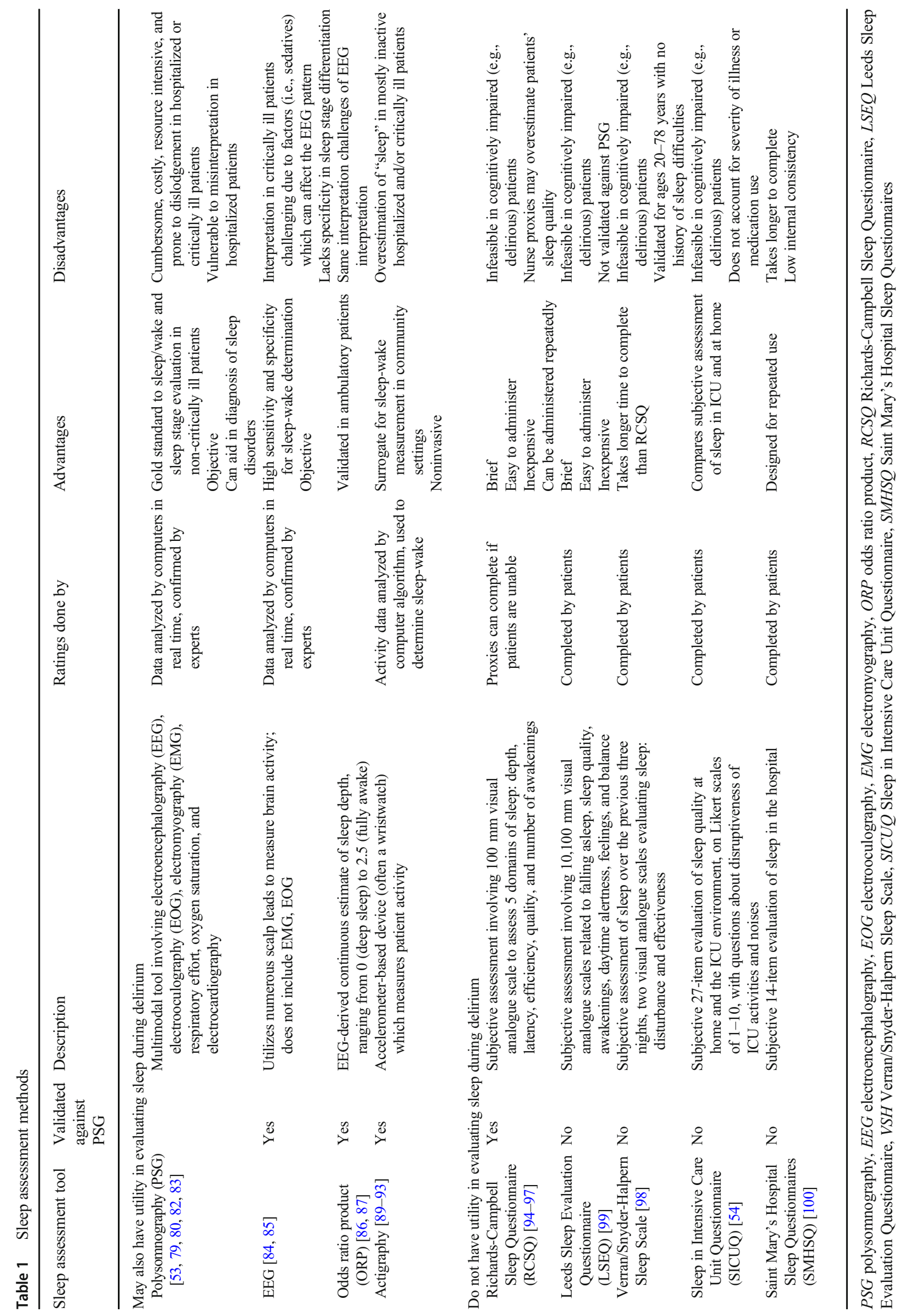


Table 2 Delirium assessment methods

\begin{tabular}{llccc}
\hline Delirium screening tool & $\begin{array}{l}\text { Criteria on which Scale was } \\
\text { based }\end{array}$ & $\begin{array}{l}\text { Number of } \\
\text { items }\end{array}$ & $\begin{array}{l}\text { Time to complete } \\
\text { (minutes) }\end{array}$ & Ratings done by \\
\hline CAM-ICU [102] & DSM-IV & 9 & $\leq 2$ & $\begin{array}{r}\text { Trained health } \\
\text { professional } \\
\text { Non-specialist staff }\end{array}$ \\
ICDSC [103] & DSM-IV & 8 & $7-10$ & Psychiatrists \\
DRS-R-98 (106) & DSM-IV & 16 & 10 & Nurses \\
NEECHAM Confusion Scale [107] & Research & 9 & 10 & Research Assistant \\
$\begin{array}{l}\text { Delirium Observation Screening Scale } \\
\quad \text { 108] }\end{array}$ & DSM-IV & 25 & $5-10$ & Nurses \\
Nursing Delirium Screening Scale [109] & Research & 5 & 1 & \\
\hline
\end{tabular}

CAM-ICU Confusion Assessment Method for the ICU, DSM Diagnostic and Statistical Manual for Mental Disorders, ICDSC Intensive Care Delirium Screening Checklist, DRS-R-98 Delirium Rating Scale-Revised 98, NEECHAM Neelon-Champagne

specificity for differentiating sleep stages [85]. In critically ill patients, EEG interpretation is especially challenging, due to marked sleep-wave fragmentation, artifact, and alteration of normal signals by common ICU issues such as sedation and illness itself.

EEG recordings have also been used to calculate an odds ratio product (ORP), a continuous estimate of sleep depth validated in ambulatory and ICU patients [86, 87]. The ORP ranges from 0 (deeply asleep) to 2.5 (fully awake), with ORP $<1.0$ predicting sleep and $>2.0$ predicting wakefulness [87]. ORP can help differentiate sleep and wake, and was used in a recent study to demonstrate that increased wakefulness and right-left hemisphere ORP concordance can predict extubation success in mechanically ventilated patients [87]. However, ORP-based sleep stage determination in hospitalized patients is limited by substantial interrater variability, similar to EEG.

In patients with delirium, EEG tends to demonstrate background slowing and increased spectral variability with periodic discharges such as triphasic waves and polymorphic delta activity [88]. Similar patterns can also be seen in nonconvulsive status epilepticus (NCSE), a mimicker of delirium [88].

\section{Actigraphy}

Actigraphy involves an accelerometer, usually housed in a wristwatch-type interface, to measure activity levels. Computer algorithms are then applied to activity data to determine sleep and wake. In community-dwelling adults, actigraphy has been validated to measure sleep [89], but has been shown to overestimate sleep in mostly inactive critically ill patients [90, 91]. However, given its minimal invasiveness, long battery life, and low cost, actigraphy has potential for large-scale, long-term sleep estimation in hospitalized patients $[92,93]$. However, similar to PSG, hospital- and ICU-specific interpretation algorithms are needed before actigraphy can be used widely in the inpatient setting.

\section{Questionnaires}

Unlike objective modes of sleep evaluation, questionnaires, though subjective, are feasible to perform on a large scale. Specifically, the Richards-Campbell Sleep Questionnaire (RCSQ), a 5-item instrument evaluating sleep depth, latency, efficiency, quality, and number of awakenings, has been validated against PSG in critically ill patients [94]. While the RCSQ has been used in several ICU-based studies to evaluate sleep, and the impact of interventions to improve sleep [95, 96], it must be completed by an alert patient, thus limiting its utility in the context of delirium. Bedside staff (i.e., nurses) can complete the RCSQ on their patients' behalf, but have been shown to overestimate patient sleep quality [97]; hence, proxy completion should be performed with caution. Other subjective methods of assessing sleep are available and include the Verran/Snyder-Halpern Sleep Scale [98], Leeds Sleep Evaluation Questionnaire (LSEQ) [99], Sleep in the Intensive Care Unit Questionnaire (SICUQ) [54], and Saint Mary's Hospital Sleep Questionnaires (SMHSQ) [100] (Table 1).

\section{Delirium Assessment Methods}

In the inpatient setting, delirium frequently goes unrecognized. Validated delirium assessment tools are essential for prompt identification and management of delirium. The Society for Critical Care Medicine (SCCM) Pain, Agitation, Delirium, Immobility and Sleep Disruption (PADIS) guidelines recommend routine screening for delirium in the ICU setting [101]. These guidelines recommend two delirium screening tools: Confusion Assessment Method for the Intensive Care Unit (CAM-ICU) [102] and Intensive Care Delirium Screening Checklist (ICDSC) [103]. Both screening 
tools involve a consciousness assessment using a standardized scale, such as Richmond Agitation Sedation Scale [104], followed by CAM-ICU or ICDSC items. The CAM-ICU involves 4 domains and takes $\leq 2 \mathrm{~min}$ to perform at the bedside, while the ICDSC involves 8 domains, 4 for current delirium symptoms and the other 4 comparing present symptoms against the previous nursing shift [105]. For patients not admitted to the ICU, the Confusion Assessment Method (CAM), which laid the foundation for the CAM-ICU, can be utilized. Other less-utilized delirium tools include the Delirium Rating Scale-Revised (DRS-R-98) [106], Neelon-Champagne (NEECHAM) Confusion Scale [107], Delirium Observation Scale [108], and Nursing Delirium Screening Scale (Table 2) $[105,109]$.

\section{Prevention and Management of Poor Sleep and Delirium}

Managing poor sleep in the hospital is challenging, particularly in older adults, but may help with delirium prevention. It is widely believed that any interventions to improve sleep should involve a multifaceted, interdisciplinary approach [110]. In a recent systematic review of sleep-focused ICU interventions to improve delirium, 6 of 10 studies reported statistically significant reductions in delirium incidence, while 3 showed a reduction in delirium duration [111]. Both pharmacologic and non-pharmacologic interventions can be employed, with minimization of sleep-disrupting medications as an important cornerstone of treatment.

Non-pharmacologic interventions to improve sleep include environmental optimization and relaxation techniques. While non-pharmacologic strategies can be resource intensive and require rigorous implementation methods to maintain sustainability, they are generally safe, low cost, and have limited side effects. Buy-in from hospital systems can be difficult, given inherent challenges in measuring improvements in sleep, and a lack of data on sleep interventions leading to improved outcomes. Data are also mixed regarding specific nonpharmacologic sleep promoting interventions in non-ICU hospitalized patients, as noted in a recent systematic review of 13 studies. More specifically, in this systematic review, 8 interventions involving relaxation techniques (4 RCTs) demonstrated a 0-38\% improvement in sleep quality, 3 involving daytime bright light a 7-18\% improvement, and two involving a sleep hygiene intervention a $0-5 \%$ improvement [112]. However, 11 of these 13 studies had a medium to high risk of bias (e.g., were limited by sampling error or selection, detection, and/or performance bias). From an environmental standpoint, noise minimization has been shown to improve subjective sleep quality ratings and includes staff-wide behavioral modification, use of ear plugs with or without eye masks, white noise, and soundproof material [113]. Daytime mobility interventions may also help with delirium prevention and may also help promote nighttime sleep, though evidence is lacking to support this notion $[114,115]$.

After non-pharmacological interventions are attempted, pharmacologic strategies to promote sleep can be considered. A key first step in this approach is the discontinuation of sleep-disrupting and/or deliriogenic medications. The American Geriatric Society Beers criteria for inappropriate medications in older adults can help identify many of these medications [116] (Table 3). In the area of delirium prevention, there is substantial interest in the role of antipsychotics; however, efficacy data are equivocal [117]. More specifically, a recent RCT examined the use of haloperidol for delirium prophylaxis showed no decrease in delirium incidence and no improvement in overall mortality [118]. Subsequently, another RCT examining the effect of haloperidol or ziprasidone versus placebo on ICU delirium found no difference in delirium-free days [21]. While recent guidelines make no recommendation regarding antipsychotics for the prevention or treatment of delirium [117], these medications may be reasonable to administer in the setting of agitation with the risk of staff or patient harm.

Aside from antipsychotics, other pharmacologic strategies to improve both sleep and delirium are being investigated. Specifically, a recent study evaluated low-dose nocturnal dexmedetomidine (an $\alpha-2$ agonist with sedative, hypnotic and analgesic properties) in mostly mechanically ventilated ICU patients had mixed results, with improvements in delirium incidence but no improvement in sleep quality [119]. Additionally, melatonin and melatonin receptor agonists are gaining attention, in part due to their favorable side-effect profile and role in re-entraining circadian rhythms [120]. Despite this attention, a Cochrane review involving 4 randomized trials and 151 participants found insufficient evidence to conclude that melatonin improves the quality and quantity of sleep in patients hospitalized in ICUs [120]. Regardless of equivocal supporting evidence, pharmacologic strategies remain a compelling area of investigation.

Whether non-pharmacological only, or combined with pharmacological interventions, a multicomponent, bundled approach is recommended for sleep and delirium improvement $[95,96,110]$. Among recent interventions, the ICUfocused "ABCDEF" bundle (Assess, Prevent and Manage Pain; Both Spontaneous Awakening and Breathing Trials; Choice of Analgesia and Sedation; Delirium Assessment, Prevention, and Management; Early Mobility and Exercise; Family Engagement/Empowerment) has gained popularity and has been associated with reductions in delirium, ventilator days, and ICU readmissions [121, 122]. Alternatively, the eCASH (Early Implementation of Comfort and Analgesia using Minimal Sedation and Humane care) concept, derived from the Pain, Agitation and Delirium guidelines, is a new approach to improve outcomes of patients in ICU [123]. 


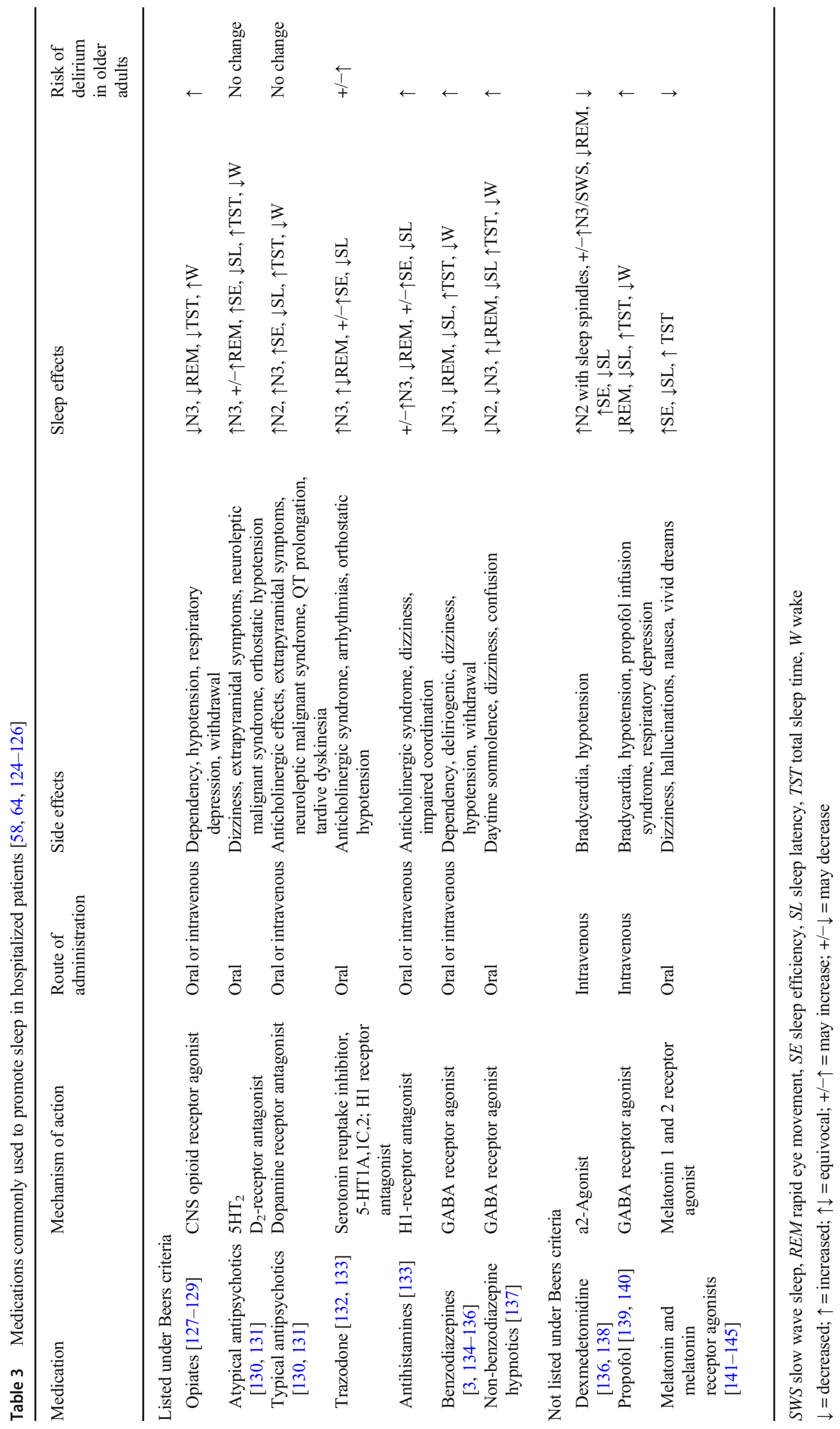


Sleep promotion is one of many components embedded within these bundles, making them particularly attractive options for intervention efforts aimed at improving sleep and delirium in hospitalized older adults. Implementing and sustaining such bundles is challenging and requires buy-in from staff and leadership, dedicated champions, an interdisciplinary team, and audit-and-feedback methods. Ongoing investigations are needed to evaluate, refine, and reproduce these invention bundles.

\section{Conclusions}

As evidence grows regarding the benefits of multicomponent interventions to improve sleep and delirium in inpatient settings, methods for intervention implementation into routine care will need to be studied. Furthermore, mechanistic research on how poor sleep or sleep/wake disruption, particularly among older adults, may lead to delirium will increase the utility of sleep-related delirium prevention efforts. Finally, larger studies are needed to evaluate the risks and potential benefits of medications and medication deprescribing in hospitalized older patients at risk for poor sleep and delirium.

Funding Information B.B.K. is supported by a Paul B. Beeson Career Development Award through the National Institute on Aging (NIA) K76AG059936. J.L.M. is supported by the National Heart Lung and Blood Institute (NHLBI) K24HL143055 and the VA Greater Los Angeles Healthcare System, Geriatric Research, Education and Clinical Center (GRECC). A.A.M is supported by NIA P30AG059299 and P30AG062429. A.M. is funded by NHLBI K24 HL132105, T32 HL134632, and R01 HL085188. UC San Diego received a philanthropic donation from Resmed in support of a sleep center. A.M. received funds from Merck for education related to drug discovery.

\section{Compliance with Ethical Standards}

Conflict of Interest None.

Human and Animal Rights This article does not contain any studies with human or animal subjects performed by any of the authors.

\section{References}

Papers of particular interest, published recently, have been highlighted as:

- Of importance

•- Of major importance

1. Han JH, Morandi A, Ely EW, Callison C, Zhou C, Storrow AB, et al. Delirium in the nursing home patients seen in the emergency department. J Am Geriatr Soc. 2009;57(5):889-94.

2. Marcantonio ER. In the clinic. Delirium. Ann Intern Med. 2011;154(11):ITC6-1, ITC6-2, ITC6-3, ITC6-4, ITC6-5,
ITC6-, ITC-7, ITC6-8, ITC6-9, ITC6-10, ITC6-1, ITC6-2, ITC6-3, ITC6-4, ITC6-5; quiz ITC6-6.

3. Pisani MA, Murphy TE, Van Ness PH, Araujo KL, Inouye SK. Characteristics associated with delirium in older patients in a medical intensive care unit. Arch Intern Med. 2007;167(15):1629-34.

4. Pandharipande P, Jackson J, Ely EW. Delirium: acute cognitive dysfunction in the critically ill. Curr Opin Crit Care. 2005;11(4): $360-8$.

5. Morandi A, Jackson JC. Delirium in the intensive care unit: a review. Neurol Clin. 2011;29(4):749-63.

6. Milbrandt EB, Deppen S, Harrison PL, Shintani AK, Speroff T, Stiles RA, et al. Costs associated with delirium in mechanically ventilated patients. Crit Care Med. 2004;32(0090-3493; 0090 3493; 4):955.

7. MacLullich AM, Beaglehole A, Hall RJ, Meagher DJ. Delirium and long-term cognitive impairment. Int Rev Psychiatry (Abingdon, England). 2009;21(1):30.

8.• Brummel NE, Jackson JC, Pandharipande PP, Thompson JL, Shintani AK, Dittus RS, et al. Delirium in the ICU and subsequent long-term disability among survivors of mechanical ventilation. Crit Care Med. 2014;42(2):369-77 Prospective cohort study demonstrating that delirium duration is associated with increased risk of disability 12 months after critical illness.

9. Ely EW, Shintani A, Truman B, Speroff T, Gordon SM, Harrell FE Jr, et al. Delirium as a predictor of mortality in mechanically ventilated patients in the intensive care unit. JAMA. 2004;291(14):1753-62.

10. Ouimet S, Kavanagh BP, Gottfried SB, Skrobik Y. Incidence, risk factors and consequences of ICU delirium. Intensive Care Med. 2007;33(1):66-73.

11.• Leslie DL, Marcantonio ER, Zhang Y, Leo-Summers L, Inouye SK. One-year health care costs associated with delirium in the elderly population. Arch Intern Med. 2008;168(1):27-32 Prospective cohort study estimating total 1-year healthcare costs of delirium in the USA ranging from of \$143-152 billion.

12. Ags/Nia Delirium Conference Writing Group PC, Faculty. The American Geriatrics Society/National Institute on aging bedsideto-bench conference: research agenda on delirium in older adults. J Am Geriatr Soc 2015;63(5):843-852.

13. Shekelle PG, MacLean CH, Morton SC, Wenger NS. Acove quality indicators. Ann Intern Med. 2001;135(8 Pt 2):653-67.

14.•- Maldonado JR. Delirium pathophysiology: an updated hypothesis of the etiology of acute brain failure. Int J Geriatr Psychiatry. 2018;33(11):1428-57 Extensive literature review of pathophysiological causes of delirium.

15. Durmer JS, Dinges DF. Neurocognitive consequences of sleep deprivation. Semin Neurol. 2005;25(1):117-29.

16. van Montfort SJT, van Dellen E, Stam CJ, Ahmad AH, Mentink $\mathrm{LJ}$, Kraan CW, et al. Brain network disintegration as a final common pathway for delirium: a systematic review and qualitative meta-analysis. Neuroimage Clin. 2019;23:101809.

17. Trzepacz PT. Is there a final common neural pathway in delirium? Focus on acetylcholine and dopamine. Semin Clin Neuropsychiatry. 2000;5(2):132-48.

18. Green AR, Reifler LM, Boyd CM, Weffald LA, Bayliss EA. Medication profiles of patients with cognitive impairment and high anticholinergic burden. Drugs Aging. 2018;35(3):223-32.

19. Hshieh TT, Fong TG, Marcantonio ER, Inouye SK. Cholinergic deficiency hypothesis in delirium: a synthesis of current evidence. J Gerontol A Biol Sci Med Sci. 2008;63(7):764-72.

20. Trzepacz PT. The neuropathogenesis of delirium. A need to focus our research. Psychosomatics. 1994;35(4):374-91.

21. Girard TD, Exline MC, Carson SS, Hough CL, Rock P, Gong $\mathrm{MN}$, et al. Haloperidol and Ziprasidone for treatment of delirium in critical illness. N Engl J Med. 2018;379(26):2506-16. 
22. Trzepacz PT. Delirium. Advances in diagnosis, pathophysiology, and treatment. Psychiatr Clin North Am. 1996;19(3):429-48.

23. van den Boogaard M, Kox M, Quinn KL, van Achterberg T, van der Hoeven JG, Schoonhoven L, et al. Biomarkers associated with delirium in critically ill patients and their relation with long-term subjective cognitive dysfunction; indications for different pathways governing delirium in inflamed and noninflamed patients. Crit Care. 2011;15(6):R297.

24. Slooter AJ, Van De Leur RR, Zaal IJ. Delirium in critically ill patients. Handb Clin Neurol. 2017;141:449-66 Review on delirium pathophysiology and nonpharmacologic and pharmacologic management in critically ill patients.

25. Seaman JS, Schillerstrom J, Carroll D, Brown TM. Impaired oxidative metabolism precipitates delirium: a study of 101 ICU patients. Psychosomatics. 2006;47(1):56-61.

26. Lipowski ZJ: Delirium: acute confusional states.New York: Oxford University Press. Delirium: Acute Confusional States.: New York: Oxford University Press; 1990.

27. Krewulak KD, Stelfox HT, Leigh JP, Ely EW, Fiest KM. Incidence and prevalence of delirium subtypes in an adult ICU: a systematic review and meta-analysis. Crit Care Med. 2018;46(12):2029-35 Recent systematic review and metaanalysis demonstrating that hypoactive delirium predominates in the ICU and is more prevalent in patients with greater illness severity.

28. Balan S, Leibovitz A, Zila SO, Ruth M, Chana W, Yassica B, et al. The relation between the clinical subtypes of delirium and the urinary level of 6-SMT. J Neuropsychiatr Clin Neurosci. 2003;15(3):363-6.

29. Yang FM, Marcantonio ER, Inouye SK, Kiely DK, Rudolph JL, Fearing MA, et al. Phenomenological subtypes of delirium in older persons: patterns, prevalence, and prognosis. Psychosomatics. 2009;50(3):248-54.

30. Inouye SK. Delirium in hospitalized older patients. Clin Geriatr Med. 1998;14(4):745-64.

31. Kiely DK, Bergmann MA, Jones RN, Murphy KM, Orav EJ, Marcantonio ER. Characteristics associated with delirium persistence among newly admitted post-acute facility patients. J Gerontol A Biol Sci Med Sci. 2004;59(4):344-9.

32. Zaal IJ, Devlin JW, Peelen LM, Slooter AJ. A systematic review of risk factors for delirium in the ICU. Crit Care Med. 2015;43(1): 40-7.

33. Ahmed S, Leurent B, Sampson EL. Risk factors for incident delirium among older people in acute hospital medical units: a systematic review and meta-analysis. Age Ageing. 2014;43(3):32633.

34. Jackson TA, Wilson D, Richardson S, Lord JM. Predicting outcome in older hospital patients with delirium: a systematic literature review. Int J Geriatr Psychiatry. 2016;31(4):392-9.

35. Davis DH, Muniz Terrera G, Keage H, Rahkonen T, Oinas M, Matthews FE, et al. Delirium is a strong risk factor for dementia in the oldest-old: a population-based cohort study. Brain. 2012;135(Pt 9):2809-16.

36. Thomason JW, Shintani A, Peterson JF, Pun BT, Jackson JC, Ely EW. Intensive care unit delirium is an independent predictor of longer hospital stay: a prospective analysis of 261 non-ventilated patients. Crit Care. 2005;9(4):R375-81.

37. Shehabi Y, Riker RR, Bokesch PM, Wisemandle W, Shintani A, Ely EW, et al. Delirium duration and mortality in lightly sedated, mechanically ventilated intensive care patients. Crit Care Med. 2010;38(12):2311-8.

38. Wolters AE, Peelen LM, Welling MC, Kok L, de Lange DW, Cremer OL, et al. Long-term mental health problems after delirium in the ICU. Crit Care Med. 2016;44(10):1808-13.

39. Kiely DK, Marcantonio ER, Inouye SK, Shaffer ML, Bergmann MA, Yang FM, et al. Persistent delirium predicts greater mortality.
J Am Geriatr Soc. 2009;57(1):55-61 Observational cohort study demonstrating that persistent delirium after admission to a post-acute care facility is an independent predictor of 1year mortality.

40. Leslie DL, Zhang Y, Holford TR, Bogardus ST, Leo-Summers LS, Inouye SK. Premature death associated with delirium at 1-year follow-up. Arch Intern Med. 2005;165(14):1657-62.

41. Ohayon MM, Carskadon MA, Guilleminault C, Vitiello MV. Meta-analysis of quantitative sleep parameters from childhood to old age in healthy individuals: developing normative sleep values across the human lifespan. Sleep. 2004;27(7):1255-73.

42. Rodriguez JC, Dzierzewski JM, Alessi CA. Sleep problems in the elderly. Med Clin North Am. 2015;99(2):431-9.

43. Foley DJ, Monjan AA, Brown SL, Simonsick EM, Wallace RB, Blazer DG. Sleep complaints among elderly persons: an epidemiologic study of three communities. Sleep. 1995;18(6):425-32.

44. Gooneratne NS, Vitiello MV. Sleep in older adults: normative changes, sleep disorders, and treatment options. Clin Geriatr Med. 2014;30(3):591-627 Review of sleep and aging, including a discussion of insomnia and sleep disordered breathing in older adults.

45. Benjafield AV, Ayas NT, Eastwood PR, Heinzer R, Ip MSM, Morrell MJ, et al. Estimation of the global prevalence and burden of obstructive sleep apnoea: a literature-based analysis. Lancet Respir Med. 2019;7(8):687-98.

46. Jaiswal SJ, Garcia S, Owens RL. Sound and light levels are similarly disruptive in ICU and non-ICU wards. J Hosp Med. 2017;12(10):798-804

47. Celik S, Oztekin D, Akyolcu N, Issever H. Sleep disturbance: the patient care activities applied at the night shift in the intensive care unit. J Clin Nurs. 2005;14(1):102-6.

48. Dobing S, Frolova N, McAlister F, Ringrose J. Sleep quality and factors influencing self-reported sleep duration and quality in the general internal medicine inpatient population. PLoS One. 2016;11(6): $\mathrm{e} 0156735$.

49. Wesselius HM, van den Ende ES, Alsma J, Ter Maaten JC, Schuit SCE, Stassen PM, et al. Quality and quantity of sleep and factors associated with sleep disturbance in hospitalized patients. JAMA Intern Med. 2018;178(9):1201-8.

50. Arora VM, Chang KL, Fazal AZ, Staisiunas PG, Meltzer DO, Zee PC, et al. Objective sleep duration and quality in hospitalized older adults: associations with blood pressure and mood. J Am Geriatr Soc. 2011;59(11):2185-6.

51. Friese RS, Diaz-Arrastia R, McBride D, Frankel H, Gentilello LM. Quantity and quality of sleep in the surgical intensive care unit: are our patients sleeping? J Trauma. 2007;63(6):1210-4.

52. Richards KC, Bairnsfather L. A description of night sleep patterns in the critical care unit. Heart Lung. 1988;17(1):35-42.

53. Gabor JY, Cooper AB, Crombach SA, Lee B, Kadikar N, Bettger $\mathrm{HE}$, et al. Contribution of the intensive care unit environment to sleep disruption in mechanically ventilated patients and healthy subjects. Am J Respir Crit Care Med. 2003;167(5):708-15.

54. Freedman NS, Kotzer N, Schwab RJ. Patient perception of sleep quality and etiology of sleep disruption in the intensive care unit. Am J Respir Crit Care Med. 1999;159(4 Pt 1):1155-62.

55.• Trompeo AC, Vidi Y, Locane MD, Braghiroli A, Mascia L, Bosma K, et al. Sleep disturbances in the critically ill patients: role of delirium and sedative agents. Minerva Anestesiol. 2011;77(6):604-12 One of the first studies to associate poor sleep quality in the ICU, defined as REM $<6 \%$, with delirium incidence.

56. Toublanc B, Rose D, Glerant JC, Francois G, Mayeux I, Rodenstein D, et al. Assist-control ventilation vs. low levels of pressure support ventilation on sleep quality in intubated ICU patients. Intensive Care Med. 2007;33(7):1148. 
57. Martin JL, Fiorentino L, Jouldjian S, Mitchell M, Josephson KR, Alessi CA. Poor self-reported sleep quality predicts mortality within one year of inpatient post-acute rehabilitation among older adults. Sleep. 2011;34(12):1715-21.

58. Kamdar BB, Needham DM, Collop NA. Sleep deprivation in critical illness: its role in physical and psychological recovery. J Intensive Care Med. 2012;27(2):97-111.

59. Dinges DF, Kribbs NB. Performing while sleepy: effects of experimentally-induced sleepiness. Sleep, sleepiness and performance. Human performance and cognition. Oxford, England: John Wiley \& Sons; 1991. p. 97-128.

60. Harrison Y, Horne JA, Rothwell A. Prefrontal neuropsychological effects of sleep deprivation in young adults-a model for healthy aging? Sleep. 2000;23(8):1067-73.

61. Mograss MA, Guillem F, Brazzini-Poisson V, Godbout R. The effects of total sleep deprivation on recognition memory processes: a study of event-related potential. Neurobiol Learn Mem. 2009;91(4):343-52.

62. Fisher S. The microstructure of dual-task interaction. 4. Sleep deprivation and the control of attention. Perception. 1980;9(3): $327-37$

63. Weinhouse GL, Schwab RJ, Watson PL, Patil N, Vaccaro B, Pandharipande $\mathrm{P}$, et al. Bench-to-bedside review: delirium in ICU patients - importance of sleep deprivation. Crit Care. 2009;13(6):234.

64. Bourne RS, Mills GH. Sleep disruption in critically ill patients pharmacological considerations. Anaesthesia. 2004;59(4):374 84.

65. Pandharipande P, Shintani A, Peterson J, Pun BT, Wilkinson GR, Dittus RS, et al. Lorazepam is an independent risk factor for transitioning to delirium in intensive care unit patients. Anesthesiology. 2006;104(1):21-6.

66. Pandharipande P, Ely EW. Sedative and analgesic medications: risk factors for delirium and sleep disturbances in the critically ill. Crit Care Clin. 2006;22(2):313-27 vii.

67. King LM, Bailey KB, Kamdar BB. Promoting sleep in critically ill patients. Nurs Crit Care 2015. 2015;10(3):37-43.

68. Flink BJ, Rivelli SK, Cox EA, White WD, Falcone G, Vail TP, et al. Obstructive sleep apnea and incidence of postoperative delirium after elective knee replacement in the nondemented elderly. Anesthesiology. 2012;116(4):788-96.

69. Gupta RM, Parvizi J, Hanssen AD, Gay PC. Postoperative complications in patients with obstructive sleep apnea syndrome undergoing hip or knee replacement: a case-control study. Mayo Clin Proc. 2001;76(9):897-905.

70. Roggenbach J, Klamann M, von Haken R, Bruckner T, Karck M, Hofer S. Sleep-disordered breathing is a risk factor for delirium after cardiac surgery: a prospective cohort study. Crit Care. 2014;18(5):477.

71.• Fadayomi AB, Ibala R, Bilotta F, Westover MB, Akeju O. A systematic review and meta-analysis examining the impact of sleep disturbance on postoperative delirium. Crit Care Med. 2018;46(12):e1204-e12 Systematic review of 12 studies suggesting that pre-existing sleep disturbances are associated with post-operative delirium.

72. Evans JL, Nadler JW, Preud'homme XA, Fang E, Daughtry RL, Chapman JB, et al. Pilot prospective study of post-surgery sleep and EEG predictors of post-operative delirium. Clin Neurophysiol. 2017;128(8):1421-5.

73. Thomas M, Sing H, Belenky G, Holcomb H, Mayberg H, Dannals $\mathrm{R}$, et al. Neural basis of alertness and cognitive performance impairments during sleepiness. I. Effects of $24 \mathrm{~h}$ of sleep deprivation on waking human regional brain activity. J Sleep Res. 2000;9(4): $335-52$.
74. Smith ME, McEvoy LK, Gevins A. The impact of moderate sleep loss on neurophysiologic signals during working-memory task performance. Sleep. 2002;25(7):784-94.

75. Gabor JY, Cooper AB, Hanly PJ. Sleep disruption in the intensive care unit. Curr Opin Crit Care. 2001;7(1):21-7.

76. van der Mast RC, van den Broek WW, Fekkes D, Pepplinkhuizen L, Habbema JD. Is delirium after cardiac surgery related to plasma amino acids and physical condition? J Neuropsychiatr Clin Neurosci. 2000;12(1):57-63.

77. Olofsson K, Alling C, Lundberg D, Malmros C. Abolished circadian rhythm of melatonin secretion in sedated and artificially ventilated intensive care patients. Acta Anaesthesiol Scand. 2004;48(6):679-84.

78. Shigeta H, Yasui A, Nimura Y, Machida N, Kageyama M, Miura $\mathrm{M}$, et al. Postoperative delirium and melatonin levels in elderly patients. Am J Surg. 2001;182(5):449-54.

79. Knauert MP, Yaggi HK, Redeker NS, Murphy TE, Araujo KL, Pisani MA. Feasibility study of unattended polysomnography in medical intensive care unit patients. Heart Lung. 2014;43(5):44552 Evaluation of unattended PSG in ICU demonstrating that only 2 of $24(7 \%)$ of patients were able to complete the entire 24-hour recording period.

80. Elliott R, McKinley S, Cistulli P, Fien M. Characterisation of sleep in intensive care using 24-hour polysomnography: an observational study. Crit Care. 2013;17(2):R46.

81. Freedman NS, Gazendam J, Levan L, Pack AI, Schwab RJ. Abnormal sleep/wake cycles and the effect of environmental noise on sleep disruption in the intensive care unit. Am J Respir Crit Care Med. 2001;163(2):451-7.

82. Watson PL, Pandharipande P, Gehlbach BK, Thompson JL, Shintani AK, Dittus BS, et al. Atypical sleep in ventilated patients: empirical electroencephalography findings and the path toward revised ICU sleep scoring criteria. Crit Care Med. 2013;41(8): 1958-67.

83. Drouot X, Roche-Campo F, Thille AW, Cabello B, Galia F, Margarit L, et al. A new classification for sleep analysis in critically ill patients. Sleep Med. 2012;13(1):7-14.

84. Vacas S, McInrue E, Gropper MA, Maze M, Zak R, Lim E, et al. The feasibility and utility of continuous sleep monitoring in critically ill patients using a portable electroencephalography monitor. Anesth Analg. 2016;123(1):206-12.

85. Lucey BP, McLeland JS, Toedebusch CD, Boyd J, Morris JC, Landsness EC, et al. Comparison of a single-channel EEG sleep study to polysomnography. J Sleep Res. 2016;25(6):625-35.

86. Dres M, Younes M, Rittayamai N, Kendzerska T, Telias I, Grieco DL, et al. Sleep and pathological wakefulness at the time of liberation from mechanical ventilation (SLEEWE). A prospective multicenter physiological study. Am J Respir Crit Care Med. 2019;199(9):1106-15 Prospective study of $\mathbf{4 4}$ mechanically ventilated patients undergoing PSG; those with higher odds ratio product (ORP), suggesting more wakefulness, were more likely to be extubated successfully.

87. Younes M, Ostrowski M, Soiferman M, Younes H, Younes M, Raneri J, et al. Odds ratio product of sleep EEG as a continuous measure of sleep state. Sleep. 2015;38(4):641-54.

88. Kaplan PW. The EEG in metabolic encephalopathy and coma. J Clin Neurophysiol. 2004;21(5):307-18.

89. Sadeh A. The role and validity of actigraphy in sleep medicine: an update. Sleep Med Rev. 2011;15(4):259-67.

90.• Schwab KE, Ronish B, Needham DM, To AQ, Martin JL, Kamdar BB. Actigraphy to evaluate sleep in the intensive care unit. A systematic review. Ann Am Thorac Soc. 2018;15(9): 1075-82 Systematic review of 13 studies that used actigraphy to evaluate sleep in critically ill patients.

91. Schwab KE, To AQ, Chang J, Ronish B, Needham DM, Martin $\mathrm{JL}$, et al. Actigraphy to measure physical activity in the intensive 
care unit: a systematic review. J Intensive Care Med. 2019: 885066619863654 . Systematic review of $\mathbf{1 6}$ studies that used actigraphy to evaluate activity in critically ill patients.

92. Kamdar BB, Kadden DJ, Vangala S, Elashoff DA, Ong MK, Martin JL, et al. Feasibility of continuous actigraphy in patients in a medical intensive care unit. Am J Crit Care. 2017;26(4):329 35.

93. Kamdar BB, Martin JL, Needham DM. Noise and light pollution in the hospital: a call for action. J Hosp Med. 2017;12(10):861-2.

94. Richards KC, O'Sullivan PS, Phillips RL. Measurement of sleep in critically ill patients. J Nurs Meas. 2000;8(2):131-44.

95. Kamdar BB, King LM, Collop NA, Sakamuri S, Colantuoni E, Neufeld KJ, et al. The effect of a quality improvement intervention on perceived sleep quality and cognition in a medical ICU. Crit Care Med. 2013;41(3):800-9.

96. Patel J, Baldwin J, Bunting P, Laha S. The effect of a multicomponent multidisciplinary bundle of interventions on sleep and delirium in medical and surgical intensive care patients. Anaesthesia. 2014;69(6):540-9.

97. Kamdar BB, Shah PA, King LM, Kho ME, Zhou X, Colantuoni $\mathrm{E}$, et al. Patient-nurse interrater reliability and agreement of the Richards-Campbell sleep questionnaire. Am J Crit Care. 2012;21(4):261-9.

98. Snyder-Halpern R, Verran JA. Instrumentation to describe subjective sleep characteristics in healthy subjects. Res Nurs Health. 1987;10(3):155-63.

99. Parrott AC, Hindmarch I. Factor analysis of a sleep evaluation questionnaire. Psychol Med. 1978;8(2):325-9.

100. Ellis BW, Johns MW, Lancaster R, Raptopoulos P, Angelopoulos N, Priest RG. The St. Mary's hospital sleep questionnaire: a study of reliability. Sleep. 1981:4(1):93-7.

101. Barr J, Fraser GL, Puntillo K, Ely EW, Gelinas C, Dasta JF, et al. Clinical practice guidelines for the management of pain, agitation, and delirium in adult patients in the intensive care unit. Crit Care Med. 2013;41(1):263-306.

102. Ely EW, Inouye SK, Bernard GR, Gordon S, Francis J, May L, et al. Delirium in mechanically ventilated patients: validity and reliability of the confusion assessment method for the intensive care unit (CAM-ICU). JAMA. 2001;286(21):2703-10.

103. Bergeron N, Dubois MJ, Dumont M, Dial S, Skrobik Y. Intensive care delirium screening checklist: evaluation of a new screening tool. Intensive Care Med. 2001;27(0342-4642; 0342-4642; 5): 859 .

104. Sessler CN, Gosnell MS, Grap MJ, Brophy GM, O'Neal PV, Keane KA, et al. The Richmond agitation-sedation scale: validity and reliability in adult intensive care unit patients. Am J Respir Crit Care Med. 2002;166(10):1338-44.

105. Grover S, Kate N. Assessment scales for delirium: a review. World J Psychiatry. 2012;2(4):58-70.

106. Trzepacz PT, Mittal D, Torres R, Kanary K, Norton J, Jimerson N. Validation of the delirium rating scale-revised-98: comparison with the delirium rating scale and the cognitive test for delirium. J Neuropsychiatr Clin Neurosci. 2001;13(2):229-42.

107. Neelon VJ, Champagne MT, Carlson JR, Funk SG. The NEECHAM confusion scale: construction, validation, and clinical testing. Nurs Res. 1996;45(6):324-30.

108. Schuurmans MJ, Shortridge-Baggett LM, Duursma SA. The delirium observation screening scale: a screening instrument for delirium. Res Theory Nurs Pract. 2003;17(1):31-50.

109. Gaudreau JD, Gagnon P, Harel F, Tremblay A, Roy MA. Fast, systematic, and continuous delirium assessment in hospitalized patients: the nursing delirium screening scale. J Pain Symptom Manag. 2005;29(4):368-75.

110. Kamdar BB, Kamdar BB, Needham DM. Bundling sleep promotion with delirium prevention: ready for prime time? Anaesthesia. 2014;69(6):527-31.
111.• Flannery AH, Oyler DR, Weinhouse GL. The impact of interventions to improve sleep on delirium in the ICU: a systematic review and research framework. Crit Care Med. 2016;44(12):2231-40 Systematic review of 10 ICU studies involving sleeppromoting interventions to improve delirium.

112.• Tamrat R, Huynh-Le MP, Goyal M. Non-pharmacologic interventions to improve the sleep of hospitalized patients: a systematic review. J Gen Intern Med. 2014;29(5):788-95 Systematic review of non-pharmacologic interventions to improve sleep in nonICU inpatients.

113. Xie H, Kang J, Mills GH. Clinical review: the impact of noise on patients' sleep and the effectiveness of noise reduction strategies in intensive care units. Crit Care. 2009;13(2):208.

114. Schweickert WD, Pohlman MC, Pohlman AS, Nigos C, Pawlik $\mathrm{AJ}$, Esbrook CL, et al. Early physical and occupational therapy in mechanically ventilated, critically ill patients: a randomised controlled trial. Lancet. 2009;373(9678):1874-82.

115. Kamdar BB, Combs MP, Colantuoni E, King LM, Niessen T, Neufeld KJ, et al. The association of sleep quality, delirium, and sedation status with daily participation in physical therapy in the ICU. Crit Care. 2016;19:261.

116.• By the American Geriatrics Society Beers Criteria Update Expert P. American Geriatrics Society 2019 Updated AGS Beers Criteria(R) for potentially inappropriate medication use in older adults. J Am Geriatr Soc. 2019;67(4):674-94. Updated American Geriatrics Society (AGS) Beers Criteria for Potentially Inappropriate Medication Use in Older Adults.

117. Neufeld KJ, Needham DM, Oh ES, Wilson LM, Nikooie R, Zhang A, et al. Antipsychotics for the prevention and treatment of delirium. Rockville (MD): AHRQ Comparative Effectiveness Reviews; 2019.

118. van den Boogaard M, Slooter AJC, Bruggemann RJM, Schoonhoven L, Beishuizen A, Vermeijden JW, et al. Effect of haloperidol on survival among critically ill adults with a high risk of delirium: the REDUCE randomized clinical trial. JAMA. 2018;319(7):680-90.

119. Skrobik Y, Duprey MS, Hill NS, Devlin JW. Low-dose nocturnal dexmedetomidine prevents ICU delirium. A randomized, placebocontrolled trial. Am J Respir Crit Care Med. 2018;197(9):114756.

120. Lewis SR, Pritchard MW, Schofield-Robinson OJ, Alderson P, Smith AF. Melatonin for the promotion of sleep in adults in the intensive care unit. Cochrane Database Syst Rev. 2018;5: CD012455.

121. Pun BT, Balas MC, Barnes-Daly MA, Thompson JL, Aldrich JM, Barr J, et al. Caring for critically ill patients with the ABCDEF bundle: results of the ICU liberation collaborative in over 15,000 adults. Crit Care Med. 2019;47(1):3-14.

122. Barnes-Daly MA, Phillips G, Ely EW. Improving hospital survival and reducing brain dysfunction at seven California community hospitals: implementing PAD guidelines via the $\mathrm{ABCDEF}$ bundle in 6,064 patients. Crit Care Med. 2017;45(2):171-8

123. Vincent JL, Shehabi Y, Walsh TS, Pandharipande PP, Ball JA, Spronk P, et al. Comfort and patient-centred care without excessive sedation: the eCASH concept. Intensive Care Med. 2016;42(6):962-71.

124. Dorsch JJ, Martin JL, Malhotra A, Owens RL, Kamdar BB. Sleep in the intensive care unit: strategies for improvement. Semin Respir Crit Care Med. 2019;40(5):614-28.

125. Alagiakrishnan K, Wiens CA. An approach to drug induced delirium in the elderly. Postgrad Med J. 2004;80(945):388-93.

126. Schweitzer PK. Drugs that disturb sleep and wakefulness. In: Kryger MH, editor. Principles and Practice of Sleep Medicine. 4th ed. Philadelphia, PA: Elsevier/Saunders; 2005. p. 499. 
127. Cronin AJ, Keifer JC, Davies MF, King TS, Bixler EO. Postoperative sleep disturbance: influences of opioids and pain in humans. Sleep. 2001;24(0161-8105; 0161-8105; 1):39.

128. Wang D, Teichtahl H. Opioids, sleep architecture and sleepdisordered breathing. Sleep Med Rev. 2007;11(1):35-46.

129. Figueroa-Ramos MI, Arroyo-Novoa CM, Lee KA, Padilla G, Puntillo KA. Sleep and delirium in ICU patients: a review of mechanisms and manifestations. Intensive Care Med. 2009;35(5):781-95.

130. Heck AH, Haffmans PM, de Groot IW, Hoencamp E. Risperidone versus haloperidol in psychotic patients with disturbing neuroleptic-induced extrapyramidal symptoms: a double-blind, multi-center trial. Schizophr Res. 2000;46(2-3):97-105.

131. Yamashita H, Morinobu S, Yamawaki S, Horiguchi J, Nagao M. Effect of risperidone on sleep in schizophrenia: a comparison with haloperidol. Psychiatry Res. 2002;109(2):137-42.

132. Ahmed QA. Effects of common medications used for sleep disorders. Critical Care Clinics. 2008;24(3):493-+.

133. NIH State of the Science Conference Statement on Manifestations and Management of Chronic Insomnia in Adults. J Clin Sleep Med. 2005;1(4):412-21.

134. Achermann P, Borbely AA. Dynamics of EEG slow wave activity during physiological sleep and after administration of benzodiazepine hypnotics. HumNeurobiol. 1987;6(0721-9075; 0721-9075; 3):203.

135. Foy A, O'Connell D, Henry D, Kelly J, Cocking S, Halliday J. Benzodiazepine use as a cause of cognitive impairment in elderly hospital inpatients. J Gerontol A Biol Sci Med Sci. 1995;50(2): M99-106.

136. Pandharipande PP, Pun BT, Herr DL, Maze M, Girard TD, Miller $\mathrm{RR}$, et al. Effect of sedation with dexmedetomidine vs lorazepam on acute brain dysfunction in mechanically ventilated patients: the MENDS randomized controlled trial. JAMA. 2007;298(22):2644.

137. Lu J, Greco MA. Sleep circuitry and the hypnotic mechanism of GABAA drugs. J Clin Sleep Med. 2006;2(2):S19-26.
138. Riker RR, Shehabi Y, Bokesch PM, Ceraso D, Wisemandle W, Koura F, et al. Dexmedetomidine vs midazolam for sedation of critically ill patients: a randomized trial. JAMA. 2009;301(5):489.

139. Bilotta F, Doronzio A, Stazi E, Titi L, Zeppa IO, Cianchi A, et al. Early postoperative cognitive dysfunction and postoperative delirium after anaesthesia with various hypnotics: study protocol for a randomised controlled trial-the PINOCCHIO trial. Trials. 2011;12:170.

140. Herregods L, Rolly G, Mortier E, Bogaert M, Mergaert C. EEG and SEMG monitoring during induction and maintenance of anesthesia with propofol. IntJClinMonitComput. 1989;6(01679945; 0167-9945; 2):67.

141. Arbon EL, Knurowska M, Dijk DJ. Randomised clinical trial of the effects of prolonged-release melatonin, temazepam and zolpidem on slow-wave activity during sleep in healthy people. $\mathrm{J}$ Psychopharmacol. 2015;29(7):764-76.

142. Zisapel N. New perspectives on the role of melatonin in human sleep, circadian rhythms and their regulation. Br J Pharmacol. 2018;175(16):3190-9.

143. Hatta K, Kishi Y, Wada K, Takeuchi T, Odawara T, Usui C, et al. Preventive effects of ramelteon on delirium: a randomized placebo-controlled trial. JAMA Psychiatry. 2014;71(4):397-403.

144. Al-Aama T, Brymer C, Gutmanis I, Woolmore-Goodwin SM, Esbaugh J, Dasgupta M. Melatonin decreases delirium in elderly patients: a randomized, placebo-controlled trial. Int J Geriatr Psychiatry. 2011;26(7):687-94.

145. Sultan SS. Assessment of role of perioperative melatonin in prevention and treatment of postoperative delirium after hip arthroplasty under spinal anesthesia in the elderly. Saudi J Anaesth. 2010;4(3):169-73.

Publisher's Note Springer Nature remains neutral with regard to jurisdictional claims in published maps and institutional affiliations. 